\section{A SOCIOLOGIA PÚBLICA NO ÂMBITO DA PRODUÇÃO E INTERVENÇÃO EM ESPORTE E LAZER NO BRASIL}

\author{
PUBLIC SOCIOLOGY IN THE DOMAIN OF ACADEMIC PRODUCTION AND \\ INTERVENTION IN SPORT AND LEISURE
}

\author{
SOCIOLOGÍA PÚBLICA EN EL ÁMBITO DE LA PRODUCCIÓN Y LA \\ INTERVENCIÓN EN DEPORTE Y OCIO EN BRASIL
}

Otavio Guimarães Tavares da Silva*, Liana Romera**, Carlos Nazareno Borges ${ }^{\star \star *}$
Palavras-chave

Sociologia pública Esporte.

Lazer.

Keywords

Public Sociology

Sports.

Leisure.
Resumo: Este artigo procurou investigar a configuração de uma sociologia pública, nos termos de Michael Burawoy, no âmbito dos estudos das políticas públicas de esporte e lazer no Brasil. Para a realização desse objetivo, foram analisados indicadores provenientes de quatro grupos de pesquisa dedicados ao tema a partir das categorias propostas por Burawoy. Os dados dão indícios de que grande parte da produção se faz a partir de sociologias críticas ou políticas, predominando a avaliação das políticas públicas. A produção no campo das políticas públicas de esporte e lazer traz contribuições pontuais, porém ainda incipientes de uma sociologia pública e da atuação dos intelectuais como profissionais orgânicos.
Abstract: : In order to discuss the academic production within sport and leisure studies in Brazil using the framework of Burawoy, this article analyzes the objectives of four research groups dedicated to public policies in this area. Mapping the academic production from this perspective, we observed some inconsistencies. Research on sport and leisure policies provides some useful contributions, however it engages only incipiently with public sociology and organic intellectualism. Much of the academic production proceeds from the perspective of critical or political sociology, and evaluation of public policy predominates.

Resumen: En este artículo se trató de investigar la configuración de una sociología pública, en los términos de Michael Burawoy, en el campo de los estudios sobre políticas públicas para el deporte y el ocio en Brasil. Para lograr este objetivo, se analizaron los indicadores de cuatro grupos de investigación dedicados al tema, con base en las categorías propuestas por Burawoy. Los datos dan evidencia de que gran parte de la producción proviene de las sociologías críticas o políticas, predominando la evaluación de las políticas públicas. La producción en el campo de las políticas públicas para el deporte y el ocio trae contribuciones específicas, aunque incipientes acerca de la sociología pública y del papel de los intelectuales como profesionales orgánicos.
* Universidade Federal do Espírito Santo, Vitoria, ES

E-mail: tavaresotavio@yahoo.com.br

** Universidade Federal do Espírito Santo, Vitoria, ES.

E-mail: liromera@uol.com.br

*** Universidade Federal do Espírito Santo, Vitoria, ES

E-mail: naza_para@yahoo.com.br

Recebido em: 30-06-2014 Aprovado em: 16-09-2014

(c) (1) () Licence 


\section{INTRODUÇÃO}

O convite feito pela revista Movimento para pensarmos uma "sociologia pública" nos termos de Michael Burawoy (2006) é, de fato, um convite à reflexão sobre as práticas e os compromissos dos intelectuais que constroem uma sociologia do esporte e do lazer no contexto das demandas e das lutas da/na sociedade contemporânea. A realização desse objetivo implica um posicionamento em relação a duas questões importantes. Em primeiro lugar, o desafio de pensar localmente a partir de categorias de análise geradas a partir de outro contexto, sem cairmos em relações assimétricas ou meramente consumistas nas trocas intelectuais. Em segundo lugar, a condição de utilizar categorias produzidas a partir de uma leitura do trabalho de sociólogos profissionais para examinar mutatis mutandis um campo que, no Brasil, é povoado por intelectuais com formações diversas que se utilizam do ferramental teórico-metodológico das ciências sociais para estudar o esporte e o lazer ${ }^{1}$.

Uma revisão da literatura indica a escassa circulação da proposta de Burawoy na sociologia do esporte e do lazer² no Brasil. Do mesmo modo, se, como veremos abaixo, o pressuposto da sociologia pública orgânica é o engajamento, o exame de histórias de vida seria 0 recurso metodológico mais adequado para a identificação de práticas profissionais. Em face desse contexto, sugere-se a carência de referências empíricas iniciais que possam apresentar indicadores para os desafios acima colocados. Assim, entendemos ser mais produtivo assumir as categorias propostas por aquele autor como forma de testar suas condições de possibilidade para pensar tanto o campo quanto as práticas dos intelectuais que o compõem. Para alcançar tal objetivo, recuperamos brevemente os elementos centrais da proposta de Burawoy assim como algumas das críticas feitas a elas. Em seguida, diante da impossibilidade momentânea de investigar as práticas propriamente ditas, examinamos os objetivos de quatro dos principais grupos de pesquisa em políticas públicas de esporte e lazer no Brasil em busca de indícios para a construção de referências iniciais. Neste contexto, assumimos a condição de efetivação das políticas públicas como um indicador indireto do estabelecimento ou não de uma sociologia pública nesta área. Este exame deu elementos significativos para pensarmos divisão do trabaIho na sociologia do esporte e do lazer.

\section{MANIFESTO BURAWOY}

Apresentado como uma conferência na American Sociological Association em 2004, o assim chamado Manifesto Burawoy foi publicado nos Estados Unidos em 2005 e no Brasil um ano depois (BURAWOY, 2006). A partir de um contexto marcado por um descompasso entre um campo sociológico majoritariamente progressista e um contexto histórico cada vez mais conservador (PERLATTO; MAIA, 2012) ou pela contradição "insuperável" entre sociologia profissional e sociologia crítica (TOURAINE, 2009, p. 245), Burawoy (2006) apresenta o que entende por sociologia pública, situando-a como um "tipo ideal" dentre outros na divisão do trabalho sociológico. De maneira sumária, podemos dizer que essa divisão comportaria uma sociologia profissional, destinada a resolver problemas científicos em ambientes universitários institucionalizados; uma sociologia orientada para políticas públicas, praticada como uma

1 A este respeito consulte-se, por exemplo Ferreira et al. (2013) e Souza; Marchi Júnior (2010).

2 Um levantamento com o uso do termo de busca ‘Burawoy' feito no Scielo e diretamente nos sítios das revistas Movimento, Revista Brasileira de Ciências do Esporte, Revista de Educação Física da UEM e Revista Brasileira de Educação Física e Esporte não encontrou nenhum artigo vinculado. 
forma de trabalho contratado por governos, ONGs e outras agências e instituições extra-acadêmicas; a sociologia crítica, realizada por intelectuais que refletiriam sobre o próprio estatuto das teorias sociais e suas implicações políticas; e a sociologia pública, entendida como uma forma de atuação política em estreita correlação com grupos sociais desfavorecidos. Em contas finais, essa divisão social do trabalho sociológico se ajusta em um modelo 2x2 (Quadro 1), embora 0 autor não elimine as possibilidades de trânsitos profissionais entre eles.

Quadro 1 - Divisão do trabalho sociológico

\begin{tabular}{ccc}
\hline & Audiência acadêmica & Audiência extra-acadêmica \\
\hline Instrumental & Profissional & Política \\
Reflexiva & Crítica & Pública \\
\hline
\end{tabular}

Fonte: Burawoy (2006, p. 20)

A sociologia pública propriamente dita comportaria duas grandes divisões: na primeira, intitulada tradicional, o sociólogo se dirigiria ao grande público em artigos de jornais, editoriais, livros e revistas, nos quais, preservando certa hierarquia comunicativa, o expert intervém no espaço público. No caso da sociologia pública orgânica, o sociólogo se engajaria mais decididamente com diversos públicos específicos, numa relação mais horizontal e de mão dupla, que permitisse 0 alargamento da experiência democrática na sociedade e na própria prática científica, o que evidencia seu caráter normativo cuja chave interpretativa é o engajamento.

Não faz parte do escopo deste texto fazer uma revisão extensa do debate que se seguiu à proposta de Burawoy, mas, devemos observar que, para além de posições normativas ou moralistas à direita e à esquerda do espectro político-acadêmico, uma série de óbices foi direcionada às suas elaborações. Para alguns de seus críticos, conceitos como "crítico"; "reflexivo" e "público" são usados de maneira ambígua e mal definida, o que impediria explorações empíricas adequadas do que seriam sociologias públicas (CALHOUM, 2005, MACLOUGHLIN; TURCOTTE, 2007). Outros entenderam que a reivindicação de um estatuto reflexivo apenas para as sociologias crítica e pública constituía um julgamento excessivamente severo da sociologia profissional (SCHEIRING, 2007). Outras críticas referem-se aos limites teóricos do modelo 2x2 para compreender como os quatro "tipos ideais" se relacionam entre si ou para examinar 0 contexto institucional nos quais se estabelecem as relações entre a sociologia e seus públicos (MACLOUGHLIN; TURCOTTE, 2007, MORROW, 2009). Um terceiro tipo de críticas se refere aos limites do modelo para pensarmos as relações entre a sociologia e outras disciplinas (a Educação Física, por exemplo), as relações com instituições no âmbito extra-acadêmico e as formas distintas de engajamento ou não (CALHOUM, 2005). Para alguns autores, a necessidade de realizar análises e definições das práticas profissionais a partir de contextos institucionais bem definidos também se estende aos contextos nacionais, uma vez que a pretensão de uma aplicação universal do modelo de divisão do trabalho de Burawoy vai de encontro às críticas do autor à dominação americana e um falso universalismo (PERLATTO; MAIA 2012).

Embora Burawoy (2006, p. 12-13) contextualize sua proposta em um "mundo [que] move-se à direita" e o "aprofundamento contínuo da desigualdade e da dominação", devemos reconhecer que o quadro no Brasil não é exatamente o mesmo, exibindo a complexidade típica das sociedades democráticas, com sinais e movimentos contraditórios entre demandas políticas liberais e a recuperação do papel do Estado como protagonista da organização social e da garantia do bem público. Ou, entre demandas da sociedade civil e a privatização do Estado 
pela força de todo o tipo de patrimonialismo. Essa distinção das condições locais não é exatamente um problema na medida em que o próprio Burawoy (2009) reconhece que os sociólogos cumprem suas missões em terrenos ideológicos e políticos, que são locais e nacionais antes de constituírem-se como globais. Como afirmou Touraine (2009, p. 250),

o que torna difícil um acordo estável é que cada tipo de pesquisa sociológica está fortemente conectada tanto à história nacional, cultural e política do país como a certa divisão do trabalho intelectual que influencia a representação da sociologia e suas fronteiras com as ciências sociais vizinhas.

Apesar dessa distinção, Touraine (2009, p. 245) assume a validade das categorias de Burawoy para pensar a "comunidade sociológica".

\section{GRUPOS DE PESQUISA EM POLÍTICAS DE ESPORTE E LAZER}

A trajetória das políticas públicas de esporte e lazer no Brasil tem sido estudada por diferentes autores (AMARAL, 2003; AREIAS, 2011; BUENO, 2008; HÚNGARO, 2008; MARCELLINO, 2008; PEIXOTO, 2007; STAREPRAVO, 2011; VERONEZ, 2005). Todavia, pareceu mais significativo analisar o campo acadêmico a partir dos grupos de pesquisa, uma vez que eles permitem recortá-lo de modo mais estruturado. Para identificar a comunidade sociológica que tem por objeto as políticas públicas de esporte e lazer, realizamos um exercício de investigação qualitativa que associou as características estudo exploratório, descritivo e explicativo, conforme as indicações de Richardson (1999). Nossa estratégia foi a de lançar mão de um olhar em recorte sobre os objetivos de trabalho de grupos cadastrados na base corrente da Plataforma Lattes do CNPq, entre os que mais têm se dedicado a investigar o policy cycle ${ }^{3}$ das políticas públicas de esporte e lazer no Brasil.

Melo e Alves Junior (2003) já haviam realizado importante trabalho de levantamento dos grupos de pesquisa atuantes no âmbito da área de Educação Física que têm por objeto 0 estudo das políticas públicas de esporte e lazer. Peixoto (2007) e Starepravo (2011) em suas teses de doutorado ofereceram significativa contribuição ao demonstrarem os grupos que mais impactavam de modo quantitativo e qualitativo no campo do esporte e lazer, através da produção de seus trabalhos nos periódicos e eventos mais reconhecidos.

Importante destacar que, no cruzamento da contribuição dos dois autores supramencionados, dá-se atenção à produção dos grupos, e não de pesquisadores individuais, uma vez que seria possível identificar alguma referência importante para o campo, mas cuja produção poderia não expressar fidedignamente o escopo do presente trabalho. Foi por meio da indicação tomada das produções coletivas que conseguimos estratificar os seguintes grupos para a nossa análise: O Grupo de Pesquisa em Lazer - GPL (Universidade Metodista de Piracicaba/SP - Unimep), ${ }^{4}$ liderado por Nelson Carvalho Marcellino e Edmur Antônio Stoppa; Grupo de Pesquisa e Formação Sociocrítica em Educação Física, Esporte e Lazer - AVANTE (Universidade Federal de Brasília/DF - UnB), liderado por Fernando Mascarenhas e Edson Marcelo Húngaro; Centro de Pesquisa em Esporte, Lazer e Sociedade (Universidade Federal do Paraná/UFPR), liderado por Wanderley Marchi

3 É comumente como se conhece o ciclo das políticas públicas em uma perspectiva sistêmica, constituindo as políticas públicas como produtos da operação do sistema político (outputs) a partir do processamento de demandas (inputs). O ciclo completo compreende novos outputs a partir da geração de resultados e respostas do contexto de implementação (feedback).

4 Este grupo foi recentemente desativado, mas consideramos que sua produção continua sendo significativa para o campo. 
Júnior; Grupo de Estudos Sociológicos, Políticos e Culturais das Práticas Corporais INSIÈME (Universidade Federal do Espírito Santo/UFES), liderado por Carlos Nazareno Ferreira Borges. ${ }^{5}$

Conforme observamos na descrição de um dos objetivos de projetos do primeiro grupo de nosso recorte - o GPL, vemos destacarem-se em suas intenções "[...] orientar ações de políticas públicas e dar novas bases para pesquisas na área". ${ }^{6}$ Tais intenções se consolidam quando encontramos em produções de membros do grupo objetivos similares reproduzidos. Já em Marcellino et al. (2007), em obra que se propunha a estudar as políticas públicas de esporte/lazer nos municípios paulistas de Campinas e Piracicaba, quando se apresentam os objetivos, argumentava-se que se estava tratando de políticas setoriais inseridas em políticas mais amplas relacionadas com a esfera de governo federal, sobretudo com as que apresentavam caráter de política social. Nesse sentido, os objetivos eram:

a- verificar a importância que a política de formação e desenvolvimento de quadros tem, como eixo da política de esporte e lazer de dois municípios do Estado de São Paulo; b- verificar quais são os componentes da política de formação e desenvolvimento de quadros desses municípios; c- estudar possíveis alternativas para melhor adequar essas políticas dentro da política geral de esporte e lazer desses municípios (MARCELLINO et al., 2007, p. 8-9).

Algo similar foi encontrado em Rodrigues e Marcellino (2011, p. 1), em estudo que objetivou "identificar e analisar a inclusão do Lazer enquanto área da política pública de Porto Alegre, no período de 1994 a 2004, buscando compreender suas diretrizes, objetivos, pressupostos e projetos implementados".

Ao tomarmos o segundo grupo do recorte - o Centro de Pesquisa em Esporte, Lazer e Sociedade (UFPR) - vimos que os objetivos anunciados para o conjunto de projetos daquele grupo são assim anunciados:

[...] investigar qual a forma de gestão das Secretarias Municipais de Esportes e Lazer dos municípios acima destacados. O principal instrumento de coleta de dados desta ação é uma entrevista estruturada com questões abertas e fechadas, realizada junto aos Secretários Municipais ou responsáveis pelos Departamentos de Esporte e Lazer das cidades. As entrevistas são compostas de três partes: A primeira investiga a Estrutura Administrativa das secretarias e/ou departamentos, focalizando suas divisões internas, a relação dos profissionais e as divisões descentralizadas. A segunda refere-se à gestão pública, direcionando as questões para o plano de governo, a participação da sociedade civil organizada e comunidade em geral na elaboração, acompanhamento e fiscalização do plano de governo. Já a terceira trata dos programas e projetos de esporte e lazer realizados nas cidades. Visa, dialogando com fontes científicas e aproximando-se dos conceitos propostos pela sociologia, discutir como são planejados e vivenciados os espaços e equipamentos de Esporte e Lazer nas cidades a serem pesquisadas. Situar, numa primeira fase, algumas questões do planejamento urbano das cidades. Visa desenvolver uma investigação de cunho descritivo dos programas e projetos de intervenção municipais públicos ofertados aos idosos, com um enfoque especial nas questões relacionadas à atividade física, esportiva e de lazer. Esta ação tem como principal instrumento de coleta de dados uma

\footnotetext{
5 Sabemos que os grupos de pesquisa que atuam no campo de estudos destacado no presente estudo têm características peculiares, como em todos os campos de estudo. Em se tratando de investigações relacionadas às políticas públicas, é relevante informar que os grupos tomados nesse trabalho, como outros que não foram selecionados, possuem matrizes teóricas (e políticas) diferenciadas. Nesse sentido, 0 GPL, o Insième e o Avante, desdobram seus estudos com fundamentação teórica de matriz gramsciana, enquanto o Centro de Pesquisa em Esporte, Lazer e Sociedade centra seus estudos fundamentados nas categorias teóricas de Pierre Bourdieu.

6 Disponível em: <http://www.unimep.br/noticias.php?nid=2113>. Acesso em: 2 maio 2014.
} 
entrevista semi-estruturada que tem sido aplicada aos responsáveis pelos programas e/ou projetos para os idosos. ${ }^{7}$

Fazendo uma busca nas produções deste grupo, vemos em Starepravo, Souza e Marchi Júnior (2011, p. 236) um estudo cujo objetivo é:

[...] contribuir com uma leitura mais refinada das políticas públicas de esporte e lazer por parte dos especialistas, através de algumas reflexões, conceitos e procedimentos metodológicos, que constituem parte das ferramentas de pesquisa do pesquisador social, particularmente aqueles que buscam uma leitura sociocultural do esporte, do lazer e das temáticas correlatas.

Continuando nossa empreita com o terceiro grupo do recorte, vamos encontrar nos objetivos do INSIÈME:

Reunir iniciativas de estudos no âmbito dos fenômenos relacionados com as práticas corporais que façam interfaces com questões políticas e com as áreas onde se manifestam, entre as quais: educação, saúde, cultura, esporte, lazer, assistência social, entre outras. A fundamentação teórica utilizada é a produzida no campo da política, priorizando-se as matrizes teóricas conceituais de política, política pública, gestão, avaliação de políticas, democratização e acesso a direitos, formação política. $^{8}$

Os estudos de Areias e Borges (2011) e Borges e Tonini (2012) do grupo supramencionado apresentam os seguintes objetivos:

[...] entender e revelar se a concepção de Lazer dos gestores e agentes sociais do Programa Esporte e Lazer da Cidade (PELC), no Município de Vitória - ES tem influência na eficiência, eficácia e efetividade social deste programa. (AREIAS; BORGES, 2011, p. 575) Através de um olhar interpretativo sobre os dados levantados da relação entre a cidade de Vitória e as modalidades esportivas de alto rendimento aqui elencadas, e de como isso repercute a favor dos cidadãos que ali vivem, pretendemos gerar material empírico para auxílio na instrumentalização de avaliação de Políticas Públicas de Esporte e Lazer no município e, dessa forma, possibilitar potencialmente a implementação dessas políticas, ou mesmo gerar outras que sejam porventura mais significativas (BORGES; TONINI, 2012, p. 283)

Por fim, o quarto grupo do recorte - o AVANTE - tem por objetivos:

Consolidar atividades de pesquisa e estudos sociocríticos referentes às temáticas da Educação Física, Esporte e Lazer na UnB, com trabalho junto a professores e alunos, especialmente, da Faculdade de Educação Física, estendendo ações à universidade e outras instituições; - Desenvolver atividades voltadas à articulação de ensino, pesquisa e extensão, com destaque para estágios, intercâmbios, projetos de extensão, seminários, práticas de pesquisa e organização de banco de dados sobre a Educação Física, o Esporte e o Lazer; - Ofertar disciplinas na graduação e pós-graduação aprofundando estudos sociocríticos sobre a Educação Física, o Esporte e o Lazer articulando a formação profissional inicial e continuada na Faculdade de Educação Física da UnB; - Estimular a produção, sistematização e difusão do conhecimento sobre Educação Física, o Esporte, o Lazer, a Política e a Formação; - Disponibilizar um espaço laboratorial, organizando, reunindo e socializando recursos materiais e didáticos aos alunos, professores e pesquisadores da UnB e outras instituições. ${ }^{9}$

7 Disponível em: <http://www.redecedes.ufpr.br/projetos.html>. Acesso em: 2 maio 2014. 
Quando visitamos alguma produção do grupo, encontramos objetivos como o anunciado em Carneiro e Mascarenhas (2013, p. 1), no qual se pretende "compreender o direcionamento da política esportiva do Distrito Federal, a partir das diferentes dimensões do esporte, tendo em vista o planejamento e o gasto com esporte no período 2008-2011, analisando a possibilidade de sua efetivação como direito social". Algo na mesma direção pode ser visto em Liao Junior (2003, p. 39), cujo estudo pretendeu investigar:

[...] os processos inerentes à gestão de políticas públicas de educação física, esporte e lazer no GDF de 1995 a 1998, durante o governo Cristovam Buarque. O desenvolvimento de princípios materializados em ações no segmento apontou perspectivas de uma gestão pautada no interesse público, na transparência, na impessoalidade e na descentralização administrativa, a despeito das contradições internas e da tardia iniciativa dos setores mais estratégicos da área no "governo democrático e popular", quanto à implementação e afirmação da educação física, do esporte e do lazer como direitos sociais.

Acreditamos que esses elementos apresentados, cuja intenção é a de mostrar a constituição dos projetos desses grupos de pesquisa em políticas públicas de esporte e lazer, assim como exemplos pontuais de suas produções, parecem se aproximar das características do que foi denominado como sociologia profissional por Burawoy (2006). Nossa crença advém da preocupação aparente em trabalhos como os dos grupos GPL e Centro de Pesquisa em Esporte, Lazer e Sociedade, em realizar estudos sistemáticos, orientados por um rigor nos protocolos suficientemente consolidados a ponto de fornecer garantias de um conhecimento com reconhecido valor acadêmico científico.

Na mesma direção do argumento supramencionado, acreditamos que os dados podem também indicar que a produção acadêmica no campo das políticas públicas de esporte e lazer pode ser compreendida nos marcos da sociologia orientada para as políticas públicas, quando percebemos a preocupação de grupos como o Insième em desenvolver estudos demarcados em realidades e territórios específicos, muito interessados em responder questões singulares que interessam a agendas também particulares de políticas públicas. Isto é, as iniciativas que se inscrevem nessa perspectiva em geral estão preocupadas com problemas locais, e podem estar centradas em uma dimensão de microssociologia que nem sempre se permite expandir para outras realidades. De modo geral, tal característica vai ao encontro do que afirmou Touraine (2009) para quem esta prática é bastante ativa na América Latina enquanto a sociologia pública seria menos visível.

Do mesmo modo, acreditamos também na existência de uma sociologia crítica, se considerarmos as intencionalidades nos estudos de grupos como o Avante, de influenciar, contribuir ou destituir a validação das políticas públicas implementadas por setores de esporte e lazer em gestões de todas as esferas de governo. As iniciativas centradas em sociologias políticas e críticas parecem estar sendo produzidas na perspectiva de influência sobre as ações das coalizões políticas que orientam as agendas nas arenas políticas de todas as esferas de governo (BUENO, 2008).

Sob os mesmos argumentos acima, podemos verificar que as políticas setoriais sobre as quais as produções se debruçam parecem desvinculadas da intencionalidade de favorecer 0 acesso ao direito social de esporte e lazer (ainda que com frequência anunciem essa intenção), sendo dessa forma descoladas do interesse público que não seja o de "aproveitar-se" de algo oferecido como se fosse um favor prestado. Nesse sentido, tem sido amplamente favorável 
o desenvolvimento de sociologias críticas e sociologias orientadas para as políticas públicas, quando a avaliação das ações proporciona retorno de maior interesse das instituições e não dos cidadãos em si. Por outro lado, não parece haver indícios de uma sociologia pública orgânica.

Já que nos reportamos ao direito social, o qual se constitui um dos principais conceitos presentes na produção acadêmica quando se discutem as políticas públicas de esporte e lazer, é mister salientarmos que o direito social não recebe o devido tratamento teórico na produção que estamos nos reportando, gerando um indício e ao mesmo tempo uma explicação para a inexistência de uma sociologia pública nesta área.

Não temos condições de mostrar neste texto os diferentes dados originados dos relatórios de gestão das mais diversas localidades investigadas pelos grupos de pesquisa que aqui tomamos, no entanto, acreditamos ser significativo evidenciar nossa afirmativa anterior, apresentando a constatação no Relatório Anual de Auditoria da Controladoria Geral da União (CGU) a respeito do Programa Esporte e Lazer da Cidade (PELC), a principal política que pretende favorecer o acesso democrático universal ao esporte e lazer em nível federal. Segundo o relatório:

Para avaliação dos resultados do Programa 1250 - Esporte e Lazer na Cidade, encontra-se descrito, tanto no SIGPLAN, quanto no Relatório de Gestão, o seguinte indicador: Taxa de Atendimento da Demanda por Esporte Recreativo e de Lazer, às Pessoas em Situação de Vulnerabilidade Social = Número de pessoas atendidas beneficiadas no Programa/Número de pessoas das famílias com renda até $1 / 2$ salário mínimo per capita e sem rendimento. Conforme informação consignada no Relatório de Gestão, o indicador em tela representa apenas 2, dentre 15 Ações relacionadas ao Programa 1250 no SIGPLAN, de forma que apresenta comprometimento de sua Utilidade, considerando não demonstrar adequadamente a amplitude e a diversidade de características do atendimento aos beneficiários de todas as Ações do Programa. Corroborando este comprometimento da utilidade do indicador, observa-se que este não apresenta informações suficientes para embasamento de decisões gerenciais relativas à gestão do Programa, tendo em vista que somente o número de pessoas beneficiadas, por si só, não se traduz na avaliação da qualidade e do impacto desses atendimentos nas comunidades atendidas, tampouco na avaliação do desempenho dos ajustes firmados, por exemplo. Dessa forma, ao se analisar o valor resultante da medição desta taxa não é possível afirmar que foi atingido o objetivo do Programa, que consiste em "ampliar, democratizar e universalizar o acesso à prática e ao conhecimento do esporte recreativo e de lazer, integrados às demais políticas públicas, favorecendo o desenvolvimento humano e a inclusão social'. (Grifo nosso).

Considerando ser este indicador o único construído para a avaliação deste Programa, não é possível que se obtenha, por meio dele, uma visão ponderada e multidimensional da execução do referido Programa.

Conforme sabemos, e os pesquisadores do campo de políticas públicas de esporte e lazer fazem questão de enfatizar, esporte e lazer adquiriram o status de direito social no Brasil a partir da Constituição Federal de 1988 (CF). No entanto, apesar da presença na listagem dos direitos sociais no Art. 6 (somente o lazer, mas pode-se considerar o esporte recreativo contemplado), e da menção no Art. 217, sobretudo no parágrafo 3ํ (aqui considerando o esporte nas suas múltiplas dimensões, inclusive como lazer), o direito social não passou por nenhuma regulamentação similar às dos outros direitos sociais. 
A mesma CF regulamentou entre outros, o direito à Saúde e à Assistência Social, por exemplo, proporcionando desdobramentos nesses setores como o Sistema Único de Saúde (SUS) e o Sistema Único de Assistência Social (SUAS). ${ }^{10}$ No entanto, apesar das demandas surgidas por ocasião da Segunda Conferência Nacional de Esporte e Lazer, realizada no ano de 2006 em Brasília e que teve como tema justamente o Sistema Nacional de Esporte e Lazer, não se conseguiu que o esporte e lazer fossem regulamentados enquanto direitos na mesma direção dos demais elencados no Art. 6 da CF.

Umas das consequências que observamos para o quadro acima descrito é o não reconhecimento das políticas de esporte e lazer como políticas sociais. Sabemos que as políticas sociais são implementadas com caráter focal, porque pretendem promover acessos de direitos àquelas pessoas às quais são restritos (BEHRING; BOSCHETTI, 2011). Nessa perspectiva, esporte e lazer não têm sido contemplados como necessidades básicas que têm de ser protegidas, embora constituam o universo da educação (outro direito social), e embora constem em leis específicas para determinados grupos sociais vulneráveis, como as crianças e adolescentes ${ }^{11}$ e idosos. ${ }^{12}$

É amplamente argumentado, nos mais diversos trabalhos dos pesquisadores vinculados aos grupos mencionados nesse texto, que muitos cidadãos estão alijados do direito de acesso ao esporte e lazer. Isso justificaria a denominação de políticas sociais para as iniciativas de ações do Poder Público, uma vez que a intenção de tais políticas seria a busca de redução ou erradicação das desigualdades sociais (DEMO, 2006). No entanto, os dados comentados sobre a constatação da CGU em relação ao PELC, baseados em informações contidas nos próprios relatórios do Ministério do Esporte, não dão conta dessa política como redução ou erradicação das desigualdades com relação ao esporte e lazer. A proporção é similar ao que acontece em contextos locais, e que pode ser encontrada nos resultados apresentados na produção que vimos nos referindo nesse texto.

Os argumentos supramencionados parecem corroborar as afirmações das teses de Mascarenhas (2003) e Veronez (2005), de que tanto as políticas públicas de esporte e lazer não têm conseguido legitimar seus objetos de intervenção enquanto direito social, quanto a sociologia crítica que delas se ocupa não parece produzir impactos sociais. Com frequência sabemos que a conquista de direitos se deu em arenas de lutas. Por exemplo, o direito de acesso à saúde em um sistema unificado, ainda que sob os diversos problemas que enfrenta, deve-se à luta travada pela reforma sanitária ao longo de três décadas (PAIM, 2007). Da mesma forma, os direitos relacionados à assistência social por meio de um sistema unificado deram-se por lutas históricas travadas por diversos agentes políticos, sobretudo os assistentes sociais, e intensificadas por ocasião da elaboração da CF de 1988 (BEHRING; BOSCHETTI, 2011).

Não se deve reduzir no processo de lutas, portanto, o papel dos agentes políticos, assim como dos intelectuais, os quais, ao realizar uma sociologia pública nos termos de Burawoy (2006), tornam-se idealmente capazes de mobilizar os públicos focais. Tais sujeitos efetivaram-se no papel de intelectuais orgânicos à maneira de Gramsci (2001), possibilitando à sociedade civil a participação na guerra de posição travada nas arenas onde são formuladas e implementadas as políticas públicas, de modo a conquistar os direitos pretendidos pelos membros dessa mesma sociedade civil.

\footnotetext{
10 Todas regulamentados por leis orgânicas posteriores ao texto complementar (Lei nํ⒏080, de 19 de setembro de 1990, e Lei № 8.742, de 7 de dezembro de 1993, respectivamente).

11 Art. 4, da Lei Lei no 8.069, de 13 de julho de 1990, Estatuto da Criança e do Adolescente.

12 Art. 3 da Lei $n^{\circ} 10.741$, de $1^{\circ}$ de outubro de 2003, Estatuto do Idoso.
} 


\section{A MODO DE FINALIZAÇÃO...}

Parece ser possível considerar a fertilidade das categorias proposta por Burawoy como uma ferramenta de análise das práticas da "comunidade" acadêmica dedicada ao estudo das políticas públicas de esporte e lazer, ainda que ela seja povoada por intelectuais de diferentes formações.

Assim, seguindo os termos desse autor, em uma primeira análise foi possível identificar indícios, entre os grupos pesquisados, de uma prática acadêmica de tipo da sociologia profissional a partir da qual se desdobram inserções no sentido de uma sociologia crítica, aqui considerada exclusivamente nos marcos das implicações políticas das teorias sociais. Por outro lado, não foram discerníveis indícios de uma produção ao modo de sociologia pública, tal como definida por Burawoy (2006).

Se buscarmos um elo entre as assertivas mencionadas no parágrafo anterior e as posições defendidas por Burawoy, talvez devêssemos pensar que seria então função da sociologia pública orgânica, no âmbito das discussões que envolvem o esporte e lazer, o exercício de favorecimento da conscientização e legitimação de tais prerrogativas, ultrapassando os limites desse direito específico, estabelecendo parcerias com outras políticas, de emprego, transporte, moradia, educação, configurando a intersetorialidade das políticas. A nosso ver, a trajetória dos agentes políticos, intelectuais orgânicos, protagonistas no âmbito do esporte e lazer, ainda está por ser historicamente consolidada como uma trajetória de conquistas.

\section{REFERÊNCIAS}

AMARAL, S. C. F. Políticas públicas de lazer e participação cidadã: entendendo o caso de Porto Alegre. 2003. Tese (Doutorado) - Educação Física, Universidade Estadual de Campinas, Campinas, 2003.

AREIAS, K. T. V. Direito social ao lazer no Brasil: Análise das contribuições da produção acadêmica difundida no campo da Educação Física. 2011. Dissertação (Mestrado) - Centro de Educação Física e Desportos, Universidade Federal do Espírito Santo, Vitória, 2011.

AREIAS, K. T. V; BORGES, C. N. F. As políticas públicas de lazer na mediação entre estado e sociedade: possibilidades e limitações. Revista Brasileira Ciências do Esporte, Florianópolis, v. 33, n. 3, p. 573-588, jul./set. 2011.

BEHRING, E. R; BOSCHETTI, I. Política social: fundamentos e história. 8. ed. São Paulo: Cortez, 2011.

BORGES, C. N. F.; TONINI, G. T. O incentivo ao esporte de alto rendimento como política pública: influências recíprocas entre cidade e esporte. Revista Brasileira Ciência e Esporte, Florianópolis, v. 34, n. 2, p. 281-296, abr.jun. 2012.

BRASIL. Estatuto da criança e do adolescente: Lei federal no 8069, de 13 de julho de 1990. Rio de Janeiro: Imprensa Oficial, 2002.

BUENO, L. Políticas Publicas do esporte no Brasil: Razões para o predomínio do alto rendimento. 2008. Tese (Doutorado) - Escola de Administração de Empresas de São Paulo, Fundação Getulio Vargas, Rio de Janeiro, 2008.

BURAWOY, M. Por uma sociologia pública. Política e Trabalho, Recife, n. 25, p. 9-50, out. 2006.

BURAWOY, M. Cultivando sociologias públicas nos terrenos nacional, regional e global. Revista de

Sociologia Política, Curitiba, v. 17, n. 34, p. 219-230, out. 2009. 
CALHOUN, C. The Promise of Public Sociology. British Journal of Sociology, v. 56, n. 3, p. 355363, 2005.

CARNEIRO, F. H. S.; MASCARENHAS, F. O direito ao esporte no Distrito Federal: entre o planejado e o executado. In: Anais do XVIII CONGRESSO BRASILEIRO DE CIÊNCIAS DO ESPORTE, 18., CONGRESSO INTERNACIONAL DE CIÊNCIAS DO ESPORTE, 5., 2013, Brasília. Brasília/DF: CBCE, 2013.

DEMO, P. Pobreza política: A pobreza mais intensa da pobreza brasileira. Campinas: Autores Associados, 2006.

FERREIRA, A. L. P. et al. Notas sobre o campo da Sociologia do Esporte: o dilema da produção científica brasileira entre as ciências humanas e da saúde. Movimento, Porto Alegre, v. 19, n. 2, p. 251-275, 2013.

GRAMSCI, A. Cadernos do Cárcere, 2. ed. Edição e tradução de Carlos Nelson Coutinho. Rio de Janeiro: Civilização Brasileira, 2001.

HÚNGARO, E. M. Trabalho, tempo livre e emancipação humana: os determinantes ontológicos das políticas sociais de lazer. 2008. Tese (Doutorado) - Educação Física, Universidade Estadual de Campinas, Campinas, 2008.

LIAO JUNIOR, R. Políticas públicas de Educação Física, esporte e lazer: tensões e desafios de um projeto contra-hegemônico no Distrito Federal, 1995 - 1998. . Revista Brasileira Ciências do Esporte, Campinas, v. 24, n. 3, p. 39-52, maio 2003.

MARCELLINO, N. C. et al. Políticas públicas de lazer - formação e desenvolvimento de pessoal: os casos de Campinas e Piracicaba-SP. Curitiba: OPUS, 2007.

MARCELLINO, N. C. (Org.). Políticas públicas de lazer. Campinas: Alínea, 2008.

MASCARENHAS, F. Lazer como prática de liberdade. Goiânia: UFG, 2003.

MCLAUGHLIN, N.; TURCOTTE, K. Trouble with Burawoy: an analytic, synthetic alternative.

Sociology, v. 41, n. 5, 813-828, 2007.

MELO, V. A; ALVES JUNIOR, E. D. Introdução ao lazer. São Paulo: Manole, 2003.

MORROW, R. A. Rethinking Burawoy's Public Sociology: A Post-Empiricist Reconstruction. In: JEFFRIES, V. (Ed.) Handbook of public sociology. Lanham, MD: Rowman and Littlefield, 2009.

PAIM, J. S. Reforma sanitária brasileira: contribuição para a compreensão e crítica Tese (Doutorado) - Instituto de Saúde Coletiva, Universidade Federal da Bahia, Salvador, 2007.

PEIXOTO, E. M. M. Estudos do lazer no Brasil: apropriação da obra de Marx e Engels. Tese (Doutorado) - Educação Física, Universidade Estadual de Campinas, Campinas, 2007.

PERLATTO, F.; MAIA, J. M. Qual sociologia pública? uma visão a partir da periferia. Lua Nova, São Paulo, n. 87, p. 83-112, 2012.

RICHARDSON, R. J. Pesquisa social: métodos e técnicas. 3. ed. São Paulo: Atlas, 1999.

RODRIGUES, R. P.; MARCELLINO, N. C. O lazer nas políticas públicas participativas de Porto Alegre: estudo das gestões municipais de 1994 A 2004. Licere, Belo Horizonte, v. 14, n. 3, set. 2011.

SCHEIRING, G. Barbarians at the open gates: public sociology and the late modern turn. The American Sociologist, v. 38, n. 3, p. 294-308, sept. 2007.

SOUZA, J. de; MARCHI JÚNIOR, W. Por uma gênese do campo da sociologia do esporte: cenários e perspectivas. Movimento, Porto Alegre, v. 16, n. 2, p. 45-70, 2010.

STAREPRAVO, F. A. Políticas públicas de esporte e lazer no Brasil: aproximações, intersecções, rupturas e distanciamentos entre os subcampos político/burocrático e científico/acadêmico. Tese (Doutorado) - Departamento de Educação Física, Universidade Federal do Paraná, Curitiba, 2011. 
STAREPRAVO, F. A.; SOUZA, J.; MARCHI JÚNIOR, W. Políticas públicas de esporte e lazer no brasil: uma proposta teórico-metodológica de análise. Movimento, Porto Alegre, v. 17, n. 3, p. 233251, jul./set. 2011.

TOURAINE, A. A sociologia pública e o fim da sociedade. Caderno CRH, Salvador, v. 22, n. 56, p. 245-254, maio/ago. 2009.

VERONEZ, L. F. C. Quando o estado joga a favor do privado: as políticas de esporte após a Constituição Federal de 1988. Tese (Doutorado) - Educação Física, Universidade Estadual de Campinas, Campinas, 2005. 